\title{
Hospital-Based Preliminary Observations of Dietary Intake and Physical Activity in Saudi Patients with Colorectal Polyps: A Call for Nutrition Care Integration after Polypectomy Procedure
}

\author{
Areej Ali Alkhaldy(i) \\ Clinical Nutrition Department, Faculty of Applied Medical Sciences, King Abdulaziz University, P.O. Box 80215, \\ Jeddah 21589, Saudi Arabia; aalkhaldy@kau.edu.sa; Tel.: +966-12-6400000 (ext. 24251) \\ Received: 13 December 2019; Accepted: 20 April 2020; Published: 22 April 2020 \\ check for \\ updates
}

\begin{abstract}
Aim: In Saudi Arabia, the incidence of colorectal cancer (CRC) is increasing. Lifestyle modification, including diet and physical activity, is as important as the standard procedure of colonoscopy screening in reducing CRC development. I explored the dietary intake, physical activity, and selected nutritional biomarkers in Saudi patients with colorectal polyps, a precursor of CRC. Methods: Thirty polypectomy patients (aged 35-84 years) were recruited from an endoscopy unit at King Abdulaziz University Hospital. Demographic, anthropometric, physical activity, and food frequency data were collected. Plasma C-reactive protein, serum 25-hydroxy vitamin D, and folate levels were measured. Results: The median body mass index (BMI) of the patients was within the overweight cut-off range. The median consumption of carbohydrate and protein was within the recommended dietary allowance (RDA). Median fat consumption was above the RDA, while median fiber intake was below the RDA. Patients met the recommended servings/day of fruits, vegetables, dairy products, and protein but exceeded the recommended intake of fats and sweets. Most patients were non-active, with an inadequate level of serum vitamin D. Conclusion: We observed several risk factors previously associated with CRC, including low levels of physical activity, serum vitamin D, and fiber intake, and high BMI and fat intake among polypectomy patients.
\end{abstract}

Keywords: colorectal cancer; dietary intake; physical activity; polypectomy; dietary risk factors

\section{Introduction}

Worldwide, colorectal cancer (CRC) is the third most common cancer and one of the most common causes of cancer-related death [1]. In Saudi Arabia, CRC is the most common cancer in men and the second most common in women, after breast cancer [2]. Colorectal adenoma (CRA) has been identified as a precursor to colorectal cancer [3]. Previous research reported a number of CRC risk factors, including genetics, ageing, and environmental factors, such as smoking, dietary habits, obesity, and physical inactivity [4,5]. However, the etiology and factors that predict the polyps' recurrence or the progression of adenomatous polyps to adenocarcinoma have not completely elucidated the underlying mechanism [6].

Observational studies have provided consistent evidence that the initial treatment for colon polyps is polyps removal via a colonoscopy procedure together with a plan for follow-up screening [7]. However, comprehensive prevention and treatment strategies, which involve a combination of secondary prevention through surveillance, and primary prevention through lifestyle modification, such as diet and physical activity, are reported to reduce the prevalence of colorectal cancer morbidity and mortality [8-10]. 
Diets rich in fruit and vegetables, whole grains, and fiber have been reported to reduce the risk of CRC due to their polyphenol, vitamin, and mineral contents, which play roles as antioxidant, anti-inflammatory, prebiotic, and antibacterial factors [11,12]. In contrast, diets high in fat, processed meats, sugar, and other refined carbohydrates, and low in vitamin D and calcium, have been reported to increase the risk of CRC $[4,11,13]$. Diet has also been reported to modulate inflammation, which plays a crucial role in CRC development [14]. Several prospective studies have reported an association between the risk of CRC and a high blood concentration of the systemic inflammatory response marker C-reactive protein (CRP) [15], suggesting a potential role for CRP as a pro-inflammatory biomarker of CRC. Inflammation also reduces the levels of serum albumin (an established marker of nutritional status), which has been associated with inadequate protein and caloric intake in patients with chronic disease, including CRC patients [16,17].

The relationship between body mass index (BMI) and CRC has also been examined [18-21]. A recent meta-analysis of 38 prospective cohort studies reported a strong correlation between BMI and colon cancer, with an $8 \%$ increased incidence of CRC per $5 \mathrm{~kg} / \mathrm{m}^{2}$ increase in BMI [18]. In contrast, there is evidence that suggests that regular physical activity is protective against CRC, and may reduce disease risk by $24 \%$ [22], and mortality following CRC diagnosis by 38\% [23]. Moreover, physical activity has been linked with the level of vitamin D (25(OH)D3) in CRC patients, with 25(OH)D3 suggested as a potential marker for physical activity in CRC patients [24,25].

CRC is an increasing public health concern in Saudi Arabia, with little being known about the associations between Saudi lifestyle factors and the risk of CRC, with no post-polypectomy nutrition care program in Saudi Arabia. Greater economic prosperity and adoption of a more Westernized lifestyle may be contributing to the increased incidence of CRC in Saudi Arabia. These lifestyle changes include rising levels of obesity (Saudi Arabia ranks 14th among the most obese nations) [26], lack of adherence to the dietary guidelines and poor dietary practices [27], and an increasingly sedentary population in which the majority are failing to attain the recommended level of physical activity [28]. However, the association between current Saudi lifestyle factors and CRC incidence has, to date, not been examined. Therefore, this preliminary study aimed to explore dietary risk factors related to colorectal cancer, physical activity, and selected nutritional biomarkers in Saudi patients with colorectal polyps, a precursor of CRC. We hypothesized that the dietary risk factors related to CRC will be identifiable among Saudi patients with colorectal polyps and the integration of nutrition care in polypectomy patient plans is necessary.

\section{Materials and Methods}

\subsection{Study Design}

A preliminary descriptive cross-sectional study was performed. Ethical approval for the study was granted by King Abdulaziz University Hospital (KAUH) research ethics committee. All participants provided informed written consent.

\subsection{Subjects and Recruitment}

The study involved patients recruited from the endoscopy unit at KAUH. Inclusion criteria comprised Saudi polypectomy patients aged $>30$ years (both males and females) who had one or more polyp removed through polypectomy, with or without a history of CRA, and who had no known existing colorectal cancer. Patients with chronic diseases, including diabetes, hyperlipidemia, hypertension, and cardiac, liver, and renal diseases, or any history of cancer were excluded.

\subsection{Study Instruments and Data Collection}

Potential patients who met the study criteria were approached before colonoscopy. At this time, for each patient, the study aims were stated, demographic (birth, sex, income, education) and anthropometric data (height, weight, BMI) were obtained by the research team according to standard 
procedures [29], and the consent form signed. After the procedure, if the physician reported that the patient had one or more polyp removed and had no known existing colorectal cancer, the patient was included in our study. Polyp type was not confirmed by histology. It was the endoscopist's macroscopic impression that the polyps were pre-cancerous or not. In addition, blood samples were taken after the procedure and before cannula removal to be sent to the laboratory for storage. The final step was collecting dietary habits and physical activity using interviewer-administered questionnaires, which were collected during follow-up appointments or via the telephone.

The food-frequency questionnaire (FFQ) was used to assess dietary habits [30]. The questionnaire consisted of three pages and took approximately $30 \mathrm{~min}$ to complete. Subjects were asked how frequently they consumed each food item or food group ("never", "1-3 times per month", "1-3 times per week", " 1 time per day", and " 2 or more times per day") and the portion sizes. The carbohydrate, protein, fat, and dietary fiber intakes were expressed as g/day; the cholesterol, saturated fatty acid, monounsaturated fatty acid, and polyunsaturated fatty acid intakes were expressed as $\mathrm{mg} /$ day. The percentage intakes of calories, macronutrients (carbohydrate, protein, and fat), and dietary fiber were also calculated. Nutrient excesses or deficits were determined by comparison with the recommended dietary allowance (RDA) references for energy and macronutrients [31]. The North American RDA references were applied because no equivalent is available for countries in the Arab region and the Dietary Guidelines for Saudis was based on Dietary Guidelines for Americans [32]. Food intake was classified by food groups (bread, cereal, rice, and pasta group; fruits, dairy, vegetables, protein, dairy product group; fats and sweets; and miscellaneous) $[33,34]$. The analysis to calculate the number of servings of each food item per day was performed using Microsoft Office Excel. This was then compared to the daily recommended servings according to the Healthy Food Palm (Similar to the USA Food Guide Pyramid), as follows: Cereal and bread (6-11 servings/day), vegetables ( $3-5$ servings/day) and fruits ( $2-4$ servings/day), milk and its products ( $2-4$ servings/day), and meat and beans ( $2-4$ servings/day). Fat and sugar were in the smallest (representing lower quantities) [32].

The physical activity questionnaire (9 questions) about weekly activities, including transport, household, and sports, was used based on that previously reported by Al-Hazzaa et al. [35]. The questionnaire had 4 categories depending on the participants' answers. The total score was measured as follows: Very active ( $\geq 40$ point), active (39-30 point), moderate active (29-20 point), and inactive $(<20$ point). Finally, blood samples were collected by the nursing staff and sent to a laboratory to analyze the C-reactive protein (CRP), vitamin $\mathrm{D}$, and folate levels.

\subsection{Statistical Analysis}

Data were analyzed using Microsoft Excel and SPSS statistical software (version 23, SPSS, Inc., Chicago, IL, USA, 2015). The data were tested for normality using an Anderson-Darling test. Descriptive statistics are presented as median and interquartile range (IQR) and ranges are also used for continuous data.

\section{Results}

\subsection{Subject Characteristics}

The demographic and anthropometric data for the 30 polypectomy patients recruited in this study are presented in Table 1. The most frequently reported characteristics for the patients were as follows: Aged between 56 and 65 years (43\%), approximately equal gender distribution (males: $n=14,53 \%$ and females: $n=16,47 \%$ ), approximately evenly drawn from across the income range, and educated to Bachelor's degree level (37\%). The median BMI was $26 \mathrm{~kg} / \mathrm{m}^{2}$ (IQR 24-28). When grouped by BMI category, $33 \%$ of patients $(n=10)$ were normal weight, $53 \%(n=16)$ were overweight, and $17 \%(n=4)$ were obese. 
Table 1. Demographic and anthropometric data $(n=30 ;$ male $=14$, female $=16)$.

\begin{tabular}{|c|c|c|}
\hline Variables & $n$ & $\%$ \\
\hline \multicolumn{3}{|l|}{ Age (years) } \\
\hline $35-45$ & 5 & 17 \\
\hline $46-55$ & 6 & 20 \\
\hline $56-65$ & 13 & 43 \\
\hline $66-75$ & 5 & 17 \\
\hline $76-85$ & 1 & 3 \\
\hline \multicolumn{3}{|l|}{ Income (Saudi Riyal /month) } \\
\hline$<5000$ & 9 & 30 \\
\hline $5000-10,000$ & 8 & 27 \\
\hline $10,000-15,000$ & 6 & 20 \\
\hline$>15,000$ & 7 & 23 \\
\hline \multicolumn{3}{|l|}{ Education } \\
\hline Uneducated & 2 & 7 \\
\hline Primary & 7 & 23 \\
\hline Secondary & 3 & 10 \\
\hline High school & 6 & 20 \\
\hline College/diploma & 11 & 37 \\
\hline Higher education & 1 & 3 \\
\hline Anthropometric & Median & IQR (Q1-Q3) \\
\hline Height $(\mathrm{cm})$ & 164 & $154-169$ \\
\hline Weight (kg) & 70 & $63-73$ \\
\hline BMI $\left(\mathrm{kg} / \mathrm{m}^{2}\right)$ & 26 & $24-28$ \\
\hline BMI category & $n$ & $\%$ \\
\hline Normal weight $\left(18.5-24.9 \mathrm{~kg} / \mathrm{m}^{2}\right)$ & 10 & 33 \\
\hline Overweight $\left(25.0-29.9 \mathrm{~kg} / \mathrm{m}^{2}\right)$ & 16 & 53 \\
\hline Obese $\left(>30.0 \mathrm{~kg} / \mathrm{m}^{2}\right)$ & 4 & 17 \\
\hline
\end{tabular}

\subsection{Dietary Assessment}

\subsubsection{Estimation of Energy and Macronutrient Intakes Using the FFQ}

The energy and macronutrient intakes of the polypectomy patients, based on the FFQ results, are given in Table 2. According to the RDA, the median consumption of carbohydrates was within the recommended range of $45 \%-65 \%(53 \%)$ and the median protein consumption was within the recommended range of $15 \%-20 \%(17 \%)$. However, the median fat consumption was above the recommended range of $25 \%-30 \%(36 \%)$, while the median fiber intake was less than the recommended intake for adults of $30 \mathrm{~g} /$ day (13 g; IQR 10-21).

Table 2. Energy and macronutrient intakes of polypectomy patients based on the food-frequency questionnaire $(n=30$; male $=14$, female $=16)$.

\begin{tabular}{cccc}
\hline & Median & IQR (Q1-Q3) & \% of Energy Intake \\
\hline Energy (kcal/day) & 1600 & $1384-2222$ & \\
Carbohydrate (g/day) & 211 & $166-305$ & 53 \\
Fat (g/day) & 65 & $49-80$ & 17 \\
Protein (g/day) & 67 & $54-83$ & \\
Fiber (g/day) & 13 & $10-21$ & \\
Cholesterol (mg/day) & 169 & $136-237$ & \\
SFA (g/day)* & 24 & $17-26$ & \\
MUFA (g/day)* & 21 & $17-27$ & \\
PUFA (g/day) & 12 & $10-22$ & \\
\hline
\end{tabular}

* SFA: saturated fatty acids; MUFA: monounsaturated fatty acids; PUFA: polyunsaturated fatty acids. 


\subsubsection{Estimation of Food Intake Using the FFQ}

Table 3 shows the food intake of the polypectomy patients (servings/day). The median intake of items in the bread, cereal, rice, and pasta group was below the recommended 6-11 servings/day ( 2.5 servings/day [IQR 1.9-4.0]). The median intakes of fruit and vegetables were within the recommended ranges of $2-4$ servings of fruit/day and 3-5 servings of vegetables/day. The protein food group (e.g., red meat, poultry, fish, eggs, beans, and nuts) intake met the recommended intake range of 2-3 servings/day. Dairy (milk, yogurt, cheese, and ice cream) intake was within the recommended intake range of 2-3 servings/day. Lastly, fats and sweets intake was above the recommended level (use sparingly) in both males ( 2.5 servings/day [IQR 2.1-3.1]) and females (2.5 servings/day [IQR 1.4-3.3]).

Table 3. Estimation of dietary intake (servings/day) in polypectomy patients based on the FFQ $(n=30$; male $=14$, female $=16$ ).

\begin{tabular}{|c|c|c|c|c|}
\hline \multirow{2}{*}{ Food Group * } & \multirow{2}{*}{ Food Items (Daily) } & \multicolumn{3}{|c|}{ Overall $(n=30)$} \\
\hline & & Median & Q1 & Q3 \\
\hline \multirow{6}{*}{$\begin{array}{l}\text { Bread, Cereal, Rice, and } \\
\text { Pasta group } \\
\text { (recommended: } 6-11 \\
\text { servings daily) }\end{array}$} & Cornflakes & 0.0 & 0.0 & 0.0 \\
\hline & Rice, kabsa, pasta, and saleeg & 0.7 & 0.4 & 1.4 \\
\hline & $\begin{array}{l}\text { White bread (e.g., white Arabic, white toast, } \\
\text { and French toast) }\end{array}$ & 0.9 & 0.3 & 1.4 \\
\hline & Brown bread & 0.2 & 0.0 & 1.0 \\
\hline & Savories (e.g., pizza, pies, chips) & 0.3 & 0.1 & 0.4 \\
\hline & Total & 2.5 & 1.9 & 4.0 \\
\hline \multirow{5}{*}{$\begin{array}{l}\text { Fruit group } \\
\text { (recommended: } 2-4 \\
\text { servings daily) }\end{array}$} & $\begin{array}{l}\text { Fruit (e.g., apples, bananas, grapes, melons, } \\
\text { and oranges) }\end{array}$ & 1.8 & 0.9 & 3.5 \\
\hline & Dried fruits & 0.1 & 0.0 & 0.2 \\
\hline & Dates (dried and fresh) & 0.2 & 0.1 & 1.0 \\
\hline & Fresh juices & 0.2 & 0.1 & 0.2 \\
\hline & Total & 3.0 & 1.5 & 4.9 \\
\hline \multirow{4}{*}{$\begin{array}{l}\text { Vegetable group } \\
\text { (recommended: } 3-5 \\
\text { servings daily) }\end{array}$} & $\begin{array}{l}\text { Salad vegetables (e.g., cucumbers, tomatoes, } \\
\text { lettuce, and peppers) }\end{array}$ & 1.7 & 1.1 & 3.8 \\
\hline & $\begin{array}{l}\text { Other vegetables (e.g., cabbage, cauliflower, } \\
\text { aubergines, okra, onions, and spinach) }\end{array}$ & 1.5 & 0.8 & 2.0 \\
\hline & Cooked, boiled, and fried potatoes & 0.2 & 0.2 & 0.3 \\
\hline & Total & 4.0 & 2.6 & 5.6 \\
\hline \multirow{8}{*}{$\begin{array}{l}\text { Protein food group } \\
\text { (recommended: } 2-3 \\
\text { servings daily) }\end{array}$} & Peas, beans, and lentils & 0.3 & 0.1 & 0.6 \\
\hline & $\begin{array}{l}\text { Nuts and seeds (e.g., peanuts, melon seeds, and } \\
\text { pistachio nuts) }\end{array}$ & 0.4 & 0.1 & 0.6 \\
\hline & Red meat (beef, lamb, brain, kidneys, and liver) & 0.3 & 0.2 & 0.4 \\
\hline & Poultry (chicken) & 0.2 & 0.2 & 1.0 \\
\hline & Meat products (e.g., shawarmas and burgers) & 0.1 & 0.0 & 0.2 \\
\hline & Fish and fish products & 0.2 & 0.1 & 0.3 \\
\hline & Egg and egg dishes & 0.4 & 0.2 & 0.4 \\
\hline & Total & 2.1 & 1.6 & 2.6 \\
\hline \multirow{5}{*}{$\begin{array}{l}\text { Dairy products group } \\
\text { (recommended: } 2-3 \\
\text { servings daily) }\end{array}$} & Milk & 0.2 & 0.1 & 1.0 \\
\hline & Cheeses & 0.8 & 0.2 & 1.8 \\
\hline & Yoghurts & 0.8 & 0.2 & 1.1 \\
\hline & Ice cream & 0.1 & 0.0 & 0.1 \\
\hline & Total & 2.4 & 1.2 & 3.1 \\
\hline \multirow{3}{*}{$\begin{array}{l}\text { Fats and sweets group } \\
\text { (recommended: } \\
\text { sparingly) }\end{array}$} & Fats (e.g., butter, olive oil, and vegetable oil) & 2.0 & 1.2 & 2.4 \\
\hline & Syrups, preserves, and sweeteners & 0.6 & 0.2 & 1.2 \\
\hline & Total & 2.5 & 1.8 & 3.2 \\
\hline \multirow{5}{*}{ Miscellaneous } & Black and green teas and coffees & 2.0 & 1.0 & 3.9 \\
\hline & Other beverages (e.g., juices and soda drinks) & 0.4 & 0.3 & 1.1 \\
\hline & Sauces & 0.2 & 0.0 & 0.3 \\
\hline & Pickles and spices & 1.3 & 0.7 & 2.0 \\
\hline & Ginger, mint, parsley, and coriander & 1.2 & 0.3 & 2.0 \\
\hline
\end{tabular}

* For food items, servings were assessed according to the number of bowls (e.g., $1 / 2$ bowl = 1 serving, 1 bowl = 2 servings, and 2 bowls or more $=4$ or more servings). ${ }^{*}$ For beverage items, servings were assessed according to the number of cups (e.g., $1 / 2$ cup $=1$ serving, 1 cup $=2$ servings, and 2 cups or more $=4$ or more servings). 


\subsection{Physical Activity Assessment}

The data from the physical activity questionnaire showed that a high percentage of the participants were inactive (Table 4). The majority of the participants $(83 \%, n=25)$ were within the inactive score range ( $<20$ point). Only $10 \%(n=3)$ of the participants were moderately active (score of 20-29) and only $7 \%$ were classed as active (score of $30-39 ; n=2$ ). None of the patients were within the very active score range (score $>40)$.

Table 4. Assessment of physical activity of the polypectomy patients $(n=30$; male $=14$, female $=16$ ).

\begin{tabular}{cc}
\hline Level (Score) & Overall $(\boldsymbol{n}=\mathbf{3 0 )}$ \\
& $\boldsymbol{n}(\mathbf{\%})$ \\
\hline Very active $(>40)$ & $0(0)$ \\
Active $(30-39)$ & $2(7)$ \\
Moderate activity $(20-29)$ & $3(10)$ \\
Non-active $(<20)$ & $25(83)$ \\
\hline
\end{tabular}

\subsection{Measurements of Serum Vitamin D, Folate, and CRP}

An inadequate level of serum 25-hydroxy vitamin D (median $47.2 \mathrm{nmol} / \mathrm{L} ; \mathrm{IQR} 29.0-76.3$ ) was detected (normal range $>75 \mathrm{nmol} / \mathrm{L}$ ). The serum folate level ( $23.1 \mathrm{nmol} / \mathrm{L}$; IQR 17.2-31.5) was within the reference range (4.5-54.3 nmol/L). Out of 21 patients, the level of CRP was raised in eight (median $11.8 \mathrm{mg} / \mathrm{dL}$; IQR 7.5-15.4) and within the normal range $(<3.0 \mathrm{mg} / \mathrm{dL})$ for the remaining 13 patients (Table 5$)$.

Table 5. Biomarkers in the polypectomy patients.

\begin{tabular}{ccc}
\hline Biomarkers & Median & IQR \\
\hline Serum 25-hydroxy vitamin D (nmol/L) & $47.2(n=24 / 30)$ & $29.0-76.3$ \\
Serum folate $(\mathrm{nmol} / \mathrm{L})$ & $23.1(n=24 / 30)$ & $17.2-31.5$ \\
C-reactive protein $(\mathrm{mg} / \mathrm{dL})$ & & \\
Normal $(n=8 / 21)$ & $<3.0$ & - \\
Raised CRP $(n=13 / 21)$ & 11.8 & $7.5-15.4$ \\
\hline
\end{tabular}

\section{Discussion}

In this study, we explored the dietary risk factors related to colorectal cancer, physical activity, and selected nutritional biomarkers of Saudi patients with colorectal polyps, a precursor of CRC. A number of common characteristics that have been previously identified as risk factors for CRC $[11,13,36]$ were observed among the polypectomy patients. These common characteristics included: (1) Exceeding the recommended dietary fat percentage $(\geq 35 \%)$ and exceeding the recommended consumption level of high-fat food items from the fats and sweets group ( $>2.5$ servings/day); (2) a low fiber intake (<30 g/day); (3) BMI $>25 \mathrm{~kg} / \mathrm{m}^{2}$; (4) low physical activity levels; and (5) low serum vitamin D levels.

Overall, our patients consumed a higher than the RDA recommended amount of fats and sweets and below the Saudi Healthy Food Palm recommended intake of whole grain food items. Interestingly, despite meeting their recommended daily servings of fruit and vegetables, fiber intake was also less than half the RDA. Information provided in the FFQ suggests this may partly be explained by the patient preference for fruit juices rather than whole fruits and vegetables. In addition, our analysis shows that patients are meeting RDA for carbohydrate, while at the same time, consuming low servings/day from the bread, cereal, rice, and pasta group. This could indicate that the shortfall in carbohydrates is being met mainly from sugars.

Studies have proposed that a diet with a high fat content increases fat emulsification (by bile acids) in the colon. The downstream effect of this is to increase the concentration of bile acids, such as deoxycholic acid, which is considered a carcinogen and might therefore increase the risk of colon 
cancer [37]. A review of 17 Asian colonoscopy-based studies with more than 40,000 individuals reported that individuals with one or more colorectal adenomas were more likely to have unfavorable cholesterol profiles at the colonoscopy time [38]. In contrast, dietary fiber reduces transit time and increases bowel viscosity, which results in an improvement in the colonic environment. Colonic fermentation of dietary fiber by microflora produces short-chain fatty acids (acetate, propionate, and butyrate) and lowers the fecal pH level [39]. Butyrate has been reported as a chemo-preventive agent [39,40]. However, a Cochrane review of randomized controlled trials found no statistically significant effect of dietary fiber intervention versus placebo or normal diet on the recurrence of colorectal adenomas [41]. Further research is therefore needed to investigate the potential benefits of fiber for CRC prevention.

Nearly $70 \%$ of our study patients were classified as overweight or obese. A prospective study to evaluate and compare the associations between BMI and colorectal adenoma incidence observed a consistent pattern of increased risk between obesity and colorectal adenoma [42]. In addition, a meta-analysis of 36 studies on the association between BMI and the risk of colorectal adenoma concluded that a 5-unit increase in BMI gave a 19\% increased relative risk of adenomas in both men and women [43]. Many prospective studies have also examined the relationship between BMI and CRC and reported an association between BMI and CRC after several years of follow up [18-21]. A recent meta-analysis of 38 prospective cohort studies reported a strong association between BMI and colon cancer, with an $8 \%$ higher incidence of CRC per $5 \mathrm{~kg} / \mathrm{m}^{2}$ increase in BMI. Moreover, CRC risk increased further with a BMI $>27 \mathrm{~kg} / \mathrm{m}^{2}$, with a stronger association for men than for women [18]. These findings suggest that maintaining a healthy weight could decrease the risk of colorectal adenoma and CRC. Therefore, it is important that lifestyle modifications that aim to improve diet and increase physical activity are introduced by dietitians after polypectomy procedures. This would reduce body weight, thus decreasing one of the risk factors for colon polyps and its recurrence.

In the present study, our patients generally reported a very low level of physical activity.

A systematic review and meta-analysis also reported a significant inverse association between physical activity and adenomatous polyps, with a $16 \%$ relative risk reduction when comparing the most and least active participants. Therefore, this evidence suggests that physical activity plays an inhibiting role in the carcinogenic process by enhancing the immune function, decreasing inflammation, and reducing insulin levels and insulin resistance [44]. McClellan et al. [45] showed that exercise led to a reduction in the number of large intestinal polyps and significantly influenced immune cell markers in mucosal tissues, decreasing the expression of macrophage and regulatory $\mathrm{T}$ cell markers and increasing the expression of cytotoxic T cell markers.

Chronic inflammation has been linked to the cause of CRC. Nevertheless, hard conclusions could not be made from the present study because only 8 out of 21 patients had an increased level of CRP. These data can be used as a "insight" to predict the inflammation status of Saudi patients with polyps, and to calculate the sample size for future studies. Most studies on the association between inflammation and CRC have been carried in Western countries, and evidence from Saudi studies is scarce.

Low serum vitamin D levels were also detected in our polypectomy patients. Vitamin D deficiency has been reported as one of the factors that plays a role in the pathogenesis of colorectal cancer [46]. The World Health Organization's International Agency for Research on Cancer has reported that there is a strong association between an individual's vitamin $\mathrm{D}$ level and the risk of colorectal cancer development and survival [47]. In addition, several observational studies have reported associations between low vitamin D levels and the incidence of, and mortality due to, CRC [48]. Mechanistic studies show that, through gene regulation, $1 \alpha, 25$-dihydroxyvitamin D3 or calcitriol (active vitamin $\mathrm{D}$ metabolite) inhibits the proliferation and promotes the epithelial differentiation of human colon carcinoma cell lines that express vitamin D receptors [49]. Therefore, improving vitamin D status could potentially contribute to reducing the risk of CRC.

It is important to integrate nutrition care into patient plans after the polypectomy procedure, as the combination of the lifestyle modification and screening will help to reduce colon adenoma 
recurrence and CRC. The American Cancer Society guidelines recommend that CRC survivors with chronic bowel problems or surgery known to affect the absorption of nutrients should be referred to a dietitian to modify their diets to maintain optimum health, and ensure sufficient levels of vitamin D and calcium [50]. In addition, the Stroll Family Cancer Prevention Centre at McGill's Jewish General Hospital is dedicated to providing specialized information and resources in different disciplines of medicine and surgery as well as in lifestyle and dietary modification. The center has a post-polypectomy nutrition clinic to help patients who are diagnosed with colon polyps to follow dietary recommendations, which have been found to reduce the polyp recurrence risk in scientific research [51].

Despite the small sample size, this is the first study examining the dietary intake and physical activity of a Saudi population at high risk of CRC, and the data generated by this study could inform the design and sample size calculation of larger follow-up studies. In addition, this pilot study highlights some important issues that need to be further investigated in order to design effective dietary interventions as a primary prevention approach to reducing the incidence of polyp recurrence risks and CRC in Saudi Arabia. Conversely, this study had five main limitations. First, this was a cross-sectional study with only 30 patients, which did not allow associations between variables to be detected. Second, the small sample limited the generalizability to represent Saudi patients with polyps. Third, no control group was included with which to compare polyp patients. Fourth, the identification of polyp types was not confirmed by histology. This variable was dependent upon physicians reporting if polyps were non-neoplastic or neoplastic after the procedure. In addition, although polyps are a risk factor for CRC, not all polyps convert to CRC; this phenomenon could have increased the bias in our study. Finally, the FFQ used in our study was not comprehensive because not all food items that may be consumed commonly in Saudi Arabia were included. Future studies must consider a validated FFQ for the Saudi population. Furthermore, the Dietary Guidelines for Saudis, which are based on the Dietary Guidelines for Americans, may not be suitable for the Saudi population, which highlights the need for Saudi guidelines that are specific for the Saudi population to reduce the risk of diet-related disease. More research, with a large-scale longitudinal approach is proposed to determine the status of factors contributing to CRC, which is of increasing public health concern in Saudi Arabia.

\section{Conclusions}

A number of previously published nutritional risk factors associated with CRC were observed in this preliminary study of polypectomy patients in Saudi Arabia, including physical inactivity, low serum vitamin D levels, high BMI, high fat intake, and low fiber intake. These findings indicate the importance of including a registered dietitian in the multidisciplinary team to provide polypectomy patients with the necessary nutritional information after a polypectomy procedure. A larger study is needed to explore the relationship between the high incidence of CRC in Saudi Arabia and the dietary intake and physical activity of the Saudi population as well as the effect of the integration of nutrition care with the screening plan on the prevention of CRA and CRC.

Funding: Deanship of Scientific Research at King Abdulaziz University, Jeddah, for the technical and financial support (grant no. J-1436-290-607-37).

Acknowledgments: I would like to acknowledge and thanks Deanship of Scientific Research at King Abdulaziz University, Jeddah, for the technical and financial support (grant no. J-1436-290-607-37). Moreover, I would like to thank Yousef A. Qari and his group from the Department of Medicine, King Abdulaziz University Hospital, King Abdulaziz University, Jeddah, Saudi Arabia for their help during the recruitment process.

Conflicts of Interest: The authors declare no conflict of interest. 


\section{References}

1. Torre, L.A.; Bray, F.; Siegel, R.L.; Ferlay, J.; Lortet-Tieulent, J.; Jemal, A. Global Cancer Statistics, 2012. CA Cancer J. Clin. 2015, 65, 87-108. [CrossRef] [PubMed]

2. Alsanea, N.; Abduljabbar, A.S.; Alhomoud, S.; Ashari, L.H.; Hibbert, D.; Bazarbashi, S. Colorectal cancer in Saudi Arabia: Incidence, survival, demographics and implications for national policies. Ann. Saudi Med. 2015, 35, 196-202. [CrossRef] [PubMed]

3. Winawer, S.J.; Zauber, A.G.; Ho, M.N.; O’Brien, M.J.; Gottlieb, L.S.; Sternberg, S.S.; Waye, J.D.; Schapiro, M.; Bond, J.H.; Panish, J.F. Prevention of colorectal cancer by colonoscopic polypectomy. The National Polyp Study Workgroup. N Engl. J. Med. 1993, 329, 1977-1981. [CrossRef] [PubMed]

4. Macrae, F. Colorectal Cancer: Epidemiology, Risk Factors, and Protective Factors. Available online: https://www.uptodate.com/contents/colorectal-cancer-epidemiology-risk-factors-and-protective-factors (accessed on 2 August 2018).

5. Wong, M.C.; Ding, H.; Wang, J.; Chan, P.S.; Huang, J. Prevalence and risk factors of colorectal cancer in Asia. Intest. Res. 2019, 17, 317-329. [CrossRef]

6. Zauber, A.G.; Winawer, S.J. Initial management and follow-up surveillance of patients with colorectal adenomas. Gastroenterol. Clin. 1997, 26, 85-101. [CrossRef]

7. Yood, M.U.; Oliveria, S.; Boyer, J.G.; Wells, K.; Stang, P.; Johnson, C.C. Colon polyp recurrence in a managed care population. Arch. Intern. Med. 2003, 163, 422-426. [CrossRef]

8. Joshu, C.E.; Parmigiani, G.; Colditz, G.A.; Platz, E.A. Opportunities for the primary prevention of colorectal cancer in the United States. Cancer Prev. Res. 2012, 5, 138-145. [CrossRef]

9. Oruç, Z.; Kaplan, M.A. Effect of exercise on colorectal cancer prevention and treatment. World J. Gastrointest. Oncol. 2019, 11, 348-366. [CrossRef]

10. Gingras, D.; Béliveau, R. Colorectal cancer prevention through dietary and lifestyle modifications. Cancer Microenviron. 2011, 4, 133-139. [CrossRef]

11. Hughes, L.A.E.; Simons, C.C.; van den Brandt, P.A.; van Engeland, M.; Weijenberg, M.P. Lifestyle, diet, and colorectal cancer risk according to (epi)genetic instability: Current evidence and future directions of molecular pathological epidemiology. Curr. Colorectal Cancer Rep. 2017, 13, 455-469. [CrossRef]

12. Ahmed, F. Effect of diet, life style, and other environmental/chemopreventive factors on colorectal cancer development, and assessment of the risks. J. Environ. Sci. Health Part C 2004, 22, 91-147. [CrossRef] [PubMed]

13. Helander, S.; Heinavaara, S.; Sarkeala, T.; Malila, N. Lifestyle in population-based colorectal cancer screening over 2-year follow-up. Eur. J. Public Health 2018, 28, 333-338. [CrossRef] [PubMed]

14. Carter, A.B.; Misyak, S.A.; Hontecillas, R.; Bassaganya-Riera, J. Dietary modulation of inflammation-induced colorectal cancer through PPAR gamma. PPAR Res. 2009. [CrossRef] [PubMed]

15. Tsilidis, K.K.; Branchini, C.; Guallar, E.; Helzlsouer, K.J.; Erlinger, T.P.; Platz, E.A. C-reactive protein and colorectal cancer risk: A systematic review of prospective studies. Int. J. Cancer 2008, 123, 1133-1140. [CrossRef] [PubMed]

16. Toriola, A.T.; Cheng, T.Y.; Neuhouser, M.L.; Wener, M.H.; Zheng, Y.; Brown, E.; Miller, J.W.; Song, X.; Beresford, S.A.; Gunter, M.J.; et al. Biomarkers of inflammation are associated with colorectal cancer risk in women but are not suitable as early detection markers. Int. J. Cancer 2013, 132, 2648-2658. [CrossRef]

17. Lai, C.C.; You, J.F.; Yeh, C.Y.; Chen, J.S.; Tang, R.; Wang, J.Y.; Chin, C.C. Low preoperative serum albumin in colon cancer: A risk factor for poor outcome. Int. J. Colorectal Dis. 2011, 26, 473-481. [CrossRef]

18. Abar, L.; Vieira, A.R.; Aune, D.; Sobiecki, J.G.; Vingeliene, S.; Polemiti, E.; Stevens, C.; Greenwood, D.C.; Chan, D.S.M.; Schlesinger, S.; et al. Height and body fatness and colorectal cancer risk: An update of the WCRF-AICR systematic review of published prospective studies. Eur. J. Nutr. 2018, 57, 1701-1720. [CrossRef]

19. Hughes, L.A.E.; Simons, C.C.; van den Brandt, P.A.; Goldbohm, R.A.; van Engeland, M.; Weijenberg, M.P. Body size and colorectal cancer risk after 16.3 years of follow-up: An analysis from the Netherlands cohort study. Am. J. Epidemiol. 2011, 174, 1127-1139. [CrossRef]

20. Kabat, G.C.; Heo, M.; Wactawski-Wende, J.; Messina, C.; Thomson, C.A.; Wassertheil-Smoller, S.; Rohan, T.E. Body fat and risk of colorectal cancer among postmenopausal women. Cancer Causes Control 2013, 24, 1197-1205. [CrossRef] 
21. Matsuo, K.; Mizoue, T.; Tanaka, K.; Tsuji, I.; Sugawara, Y.; Sasazuki, S.; Nagata, C.; Tamakoshi, A.; Wakai, K.; Inoue, M.; et al. Association between body mass index and the colorectal cancer risk in Japan: Pooled analysis of population-based cohort studies in Japan. Ann. Oncol. 2012, 23, 479-490. [CrossRef]

22. Shaw, E.; Farris, M.S.; Stone, C.R.; Derksen, J.W.G.; Johnson, R.; Hilsden, R.J.; Friedenreich, C.M.; Brenner, D.R. Effects of physical activity on colorectal cancer risk among family history and body mass index subgroups: A systematic review and meta-analysis. BMC Cancer 2018, 18, 71. [CrossRef] [PubMed]

23. Van Blarigan, E.L.; Meyerhardt, J.A. Role of physical activity and diet after colorectal cancer diagnosis. J. Clin. Oncol. 2015, 33, 1825-1834. [CrossRef] [PubMed]

24. Scragg, R.; Camargo, C.A. Frequency of leisure-time physical activity and serum 25-hydroxyvitamin D levels in the US population: Results from the Third National Health and Nutrition Examination Survey. Am. J. Epidemiol. 2008, 168, 577-586. [CrossRef] [PubMed]

25. Skender, S.; Bohm, J.; Schrotz-King, P.; Chang-Claude, J.; Siegel, E.M.; Steindorf, K.; Owen, R.W.; Ose, J.; Hoffmeister, M.; Brenner, H.; et al. Plasma 25-hydroxyvitamin D-3 levels in colorectal cancer patients and associations with physical activity. Nutr. Cancer 2017, 69, 229-237. [CrossRef] [PubMed]

26. World Health Organization-Noncommunicable Diseases (NCD) Country Profiles. 2018. Available online: https://www.who.int/nmh/countries/sau_en.pdf?ua=1 (accessed on 4 February 2019).

27. Moradi-Lakeh, M.; El Bcheraoui, C.; Afshin, A.; Daoud, F.; AlMazroa, M.A.; Al Saeedi, M.; Basulaiman, M.; Memish, Z.A.; Al Rabeeah, A.A.; Mokdad, A.H. Diet in Saudi Arabia: Findings from a nationally representative survey. Public Health Nutr. 2017, 20, 1075-1081. [CrossRef] [PubMed]

28. Al-Hazzaa, H.M. Physical inactivity in Saudi Arabia revisited: A systematic review of inactivity prevalence and perceived barriers to active living. Int. J. Health Sci. 2018, 12, 50-64.

29. Lohman, T.; Roche, A.; Martorell, R. Anthropometric Standardization Reference Manual; Human Kinetics: Champaign, IL, USA, 1988.

30. Alissa, E.M.; Bahjri, S.M.; Al-Ama, N.; Ahmed, W.H.; Starkey, B.; Ferns, G.A.A. Dietary vitamin A may be a cardiovascular risk factor in a Saudi population. Asia Pac. J. Clin. Nutr. 2005, 14, 137-144.

31. Zello, G.A. Dietary Reference Intakes for the macronutrients and energy: Considerations for physical activity. Appl. Physiol. Nutr. Metab. 2006, 31, 74-79. [CrossRef]

32. Ministry of Health. The Dietary Guidelines for Saudis. Available online: https://www.moh.gov.sa/en/ Ministry/MediaCenter/Publications/Pages/Publications-2013-01-15.aspx (accessed on 16 March 2019).

33. Alkhaldy, A. Inter-Individual Variability of Polyphenol Metabolism and Colonic Health. Ph.D. Thesis, University of Glasgow, Glasgow, UK, 2014.

34. Alkhaldy, A.A.; Rizq, N.K.; Del Jaylan, S.A.; Alkendi, E.A.; Alghamdi, W.M.; Alfaraidi, S.M. Dietary Intake and Physical Activity in Relation to Insulin Resistance in Young Overweight Saudi Females: An Exploratory Pilot Study. Prev. Nutr. Food Sci. 2019, 24, 373-380. [CrossRef]

35. Al-Hazzaa HM, A.-A.M. A Self-reported questionnaire for the assessment of physical activity in youth 15-25 years: Development, reliability and construct validity. Arab J. Food Nutr. 2003, 4, 279-291.

36. Zhang, Q.L.; Zhao, L.G.; Li, H.L.; Gao, J.; Yang, G.; Wang, J.; Zheng, W.; Shu, X.O.; Xiang, Y.B. The joint effects of major lifestyle factors on colorectal cancer risk among Chinese men: A prospective cohort study. Int. J. Cancer 2018, 142, 1093-1101. [CrossRef] [PubMed]

37. Bernstein, C.; Holubec, H.; Bhattacharyya, A.K.; Nguyen, H.; Payne, C.M.; Zaitlin, B.; Bernstein, H. Carcinogenicity of deoxycholate, a secondary bile acid. Arch. Toxicol. 2011, 85, 863-871. [CrossRef] [PubMed]

38. Øines, M.; Helsingen, L.M.; Bretthauer, M.; Emilsson, L. Epidemiology and risk factors of colorectal polyps. Best Pract. Res. Clin. Gastroenterol. 2017, 31, 419-424. [CrossRef] [PubMed]

39. Encarnacao, J.C.; Abrantes, A.M.; Pires, A.S.; Botelho, M.F. Revisit dietary fiber on colorectal cancer: Butyrate and its role on prevention and treatment. Cancer Metastasis Rev. 2015, 34, 465-478. [CrossRef]

40. Tuan, J.; Chen, Y.X. Dietary and Lifestyle Factors Associated with Colorectal Cancer Risk and Interactions with Microbiota: Fiber, Red or Processed Meat and Alcoholic Drinks. Gastrointest. Tumors 2016, 3, 17-24. [CrossRef]

41. Yao, Y.; Suo, T.; Andersson, R.; Cao, Y.; Wang, C.; Lu, J.; Chui, E. Dietary fibre for the prevention of recurrent colorectal adenomas and carcinomas. Cochrane Database Syst. Rev. 2017, 1. [CrossRef]

42. Kitahara, C.M.; Berndt, S.I.; de González, A.B.; Coleman, H.G.; Schoen, R.E.; Hayes, R.B.; Huang, W.Y. Prospective investigation of body mass index, colorectal adenoma, and colorectal cancer in the prostate, lung, colorectal, and ovarian cancer screening trial. J. Clin. Oncol. 2013, 31, 2450-2459. [CrossRef] 
43. Ben, Q.; An, W.; Jiang, Y.; Zhan, X.; Du, Y.; Cai, Q.C.; Gao, J.; Li, Z. Body mass index increases risk for colorectal adenomas based on meta-analysis. Gastroenterology 2012, 142, 762-772. [CrossRef]

44. Wolin, K.Y.; Yan, Y.; Colditz, G.A. Physical activity and risk of colon adenoma: A meta-analysis. Br. J. Cancer 2011, 104, 882-885. [CrossRef]

45. McClellan, J.L.; Steiner, J.L.; Day, S.D.; Enos, R.T.; Davis, M.J.; Singh, U.P.; Murphy, E.A. Exercise effects on polyp burden and immune markers in the Apc (Min+) mouse model of intestinal tumorigenesis. Int. J. Oncol. 2014, 45, 861-868. [CrossRef]

46. Bryce, C. Association of 25-OH Vitamin D Status with Findings on Screening Colonoscopy. Mil. Med. 2018, 183, 547-551. [CrossRef] [PubMed]

47. Grant, W.B. A critical review of Vitamin D and Cancer: A report of the IARC Working Group. Dermatoendocrinol 2009, 1, 25-33. [CrossRef] [PubMed]

48. Mahendra, A.; Karishma, B.K.C.; Sharma, T.; Bansal, N.; Bansal, R.; Gupta, S. Vitamin D and gastrointestinal cancer. J. Lab. Physicians 2018, 10, 1-5. [CrossRef] [PubMed]

49. Ferrer-Mayorga, G.; Larriba, M.; Crespo, P.; Muñoz, A. Mechanisms of action of vitamin D in colon cancer. J. Steroid Biochem. 2018, 185, 1-6. [CrossRef]

50. El-Shami, K.; Oeffinger, K.C.; Erb, N.L.; Willis, A.; Bretsch, J.K.; Pratt-Chapman, M.L.; Cannady, R.S.; Wong, S.L.; Rose, J.; Barbour, A.L.; et al. American Cancer Society colorectal cancer survivorship care guidelines. CA Cancer J. Clin. 2015, 65, 428-455. [CrossRef]

51. Division of Cancer Prevention. Post Polypectomy Nutrition Clinic. Available online: https://www.mcgill.ca/ cancerprev/clinical/post-polypectomy-nutrition-clinic (accessed on 3 June 2019).

(C) 2020 by the author. Licensee MDPI, Basel, Switzerland. This article is an open access article distributed under the terms and conditions of the Creative Commons Attribution (CC BY) license (http://creativecommons.org/licenses/by/4.0/). 